as well as statistics. In the fourth and fifth chapters, on diagnosis and historytaking, he is less controversial, but they are still written in stimulating fashion.

This stimulating book requires students to read one or two of $\mathrm{Dr}$ Pappworth's more provocative sections which will undoubtedly lead to a lively debate with most groups of students. The balance of the clinical material is, however, very much oriented towards specialist practice with disorders such as tricuspid regurgitation described in detail.

The book therefore is a useful antidote to many modern texts but needs to be read in conjunction with other texts which are more conventional in style and content to obtain a broad view of medicine.

J A MUIR GRAY, MD, MRCGP, MRCP(Glas), FFCM,

Community Physician, Oxfordshire Health Authority

\section{Health and Human Values: a Guide to Making Your Own Decisions}

Frank Harron, John Burnside, and Tom Beauchamp, London, 196 pages, $£ 6.95$ paperback, Yale University Press, 1983.

Drawing from their respective disciplines the three authors - an educationalist, an internist, and a philosopher - have constructed a very useful guidebook to philosophical discourse in medicine. The overall objective of the book is to broaden discussion on recent biomedical developments, with particular emphasis on the human values dimension of medical education. In accord with this objective the opening chapter outlines procedures for analysing problems in the sphere of practical reasoning and provides helpful guidelines for reaching moral decisions. Anyone looking for answers to specific moral questions will, however, be disappointed. The general idea behind this book is not to argue for any particular proposal, but to present the reader with the main issues in biomedical ethics, together with the analytical tools for dealing with them, in as broad a context as possible. As such the merit of this book is primarily pedagogical.

The second chapter covers fairly familiar ground: it assesses arguments concerning the value and rights of human life in the context of decisionmaking with regard to abortion and other prenatal procedures. The next two chapters focus on moral decisionmaking about life and death. This includes an objective, but perhaps inconclusive, summary of recent opinions concerning the status of brain death and criteria for the loss of human personhood. The remaining chapters consist of well-informed accounts of the arguments about rights in the context of health-care. The final chapter deals with some of the controversies in recent work in applied genetics.

One of the benefits of crossdisciplinary work of this kind is that the philosophical discourse is free from science-fiction speculation and is generated out of real problems. Each chapter begins with an actual case study from medical practice which effectively illuminates the moral problems under discussion. The structure of each chapter has been designed with the interests of practical students in mind. Familiar case studies are presented and followed by a list of key questions for discussion. Then follows an analytical survey of the issues and a group of selected readings drawn from a wide range of disciplines. Each chapter concludes with an annotated bibliography.

This is a thoroughly researched book with a large reliable index, bibliographical charts and tables which highlight important points. It is a workbook which will be of considerable value for leaders of study groups interested in biomedical ethical issues.

\section{David Lamb is a Lecturer in Philosophy at the University of Manchester. He is also Editor of the journal, Explorations in} Medicine.

\section{Medical Ethics}

Peter Doherty, 84 pages, Bristol, $£ 1.00$, postage extra if overseas, Guild of Catholic Doctors, 1983.

The aim of this work is to expound Catholic moral teaching on medicomoral issues and apply that teaching to new trends in medicine, thus providing for the 1980s what Fr A Bonner's The Catholic Doctor provided for the '40s and '50s. But Dr Doherty could have succeeded only partially in this task, since the sheer brevity of his volume allows no really detailed consideration of any of the topics treated. Also, there are some weaknesses in the book, of which two deserve to be mentioned at the outset. First, the organisation and presentation of the book have a certain amateurish, even careless, quality (for instance, the subtitle, Contribution to Medical Ethics, repeats the main title surely unintended - moreover this subtitle appears only on the cover, not on the title page!). In places the author's style is awkward, sometimes even grammatically faulty, and occasionally his thoughts are expressed unclearly (for example the first sentence on $\mathrm{p}$ ix). Secondly, Dr Doherty is not entirely at home with philosophical terminology and ways of arguing, and it is a pity that he did not collaborate more closely with one or more professional philosophers. As it is, the book is distinctly stronger on the medical side than on the philosophical side, and so the best chapters are those in which the author draws on his long medical experience. These are the chapters entitled Transmission of Life, Manipulation of Life (on modern psychiatry), Termination of Life and The CostBenefit Equation (on problems of resource allocation). Also, the six case studies discussed at the end of the book are representative of problems encountered in day-to-day practice and Dr Doherty's comments on each of them are valuable.

Since the book is intended primarily as a guide for Catholic doctors (as the Master of the Guild of Catholic Doctors makes clear in his preface, on $p$ viii), the author is at pains to expound unambiguously a Catholic viewpoint on all the contentious matters which can arise in day-to-day practice, particularly on matters such as contraception, sterilisation, abortion, artificial insemination and in vitro fertilisation where the Catholic view is not shared by many other people. In this Dr Doherty largely succeeds, and indeed his short summaries of Catholic teachings on contraception ( $p$ 25), organ transplantation (pp 29-30), transsexual surgery (p 31) and abortion (pp 45-50) are clear and to the point. On the other hand there is a disappointing lack of attention to in vitro fertilisation (a single paragraph on p 33). But again, the treatment of the philosophical issues at stake is not equal to that of the medical issues. So, for instance, the first chapter, on Theories of Ethics, gives an unsatisfactory account of the ethical theories surveyed - Emotivist Ethics, Utilitarianism and Duty Ethics. Here the emotive theory appears to be misrepresented as the view that we typically respond to moral problems by acting on immediate emotional impulse, without pausing to reflect 
before we act. All the same, the book is to be welcomed for the valuable features which it undoubtedly contains. It is to be hoped that if there is a second edition some of the philosophical reasoning employed will be considerably tightened.

A final comment on a particular claim of the author's. Is it true to say that 'When we come to [the question of] . . . what criteria are to be used to determine whether death has occurred, we are confronted with a very technical medical issue, for which only those within the medical profession can provide the answer' (p 29)? Surely we must distinguish between two distinct questions here: first, 'What are the criteria for death?', and secondly, 'Do the criteria apply in the case of this particular human body? The doctor is presumably the person who must answer the second question, but he is not indubitably the sole authority on the first.

F J FITZPATRICK Education and Research Officer, The Linacre Centre for the Study of the Ethics of Health Care, London

\section{The Bitter Pill}

Ellen Grant, 184 pages, London, £7.95, Elm Tree Books/Hamish Hamilton Ltd, 1985.

The dust jacket for this book (pillburning on one side and shock-horror newspaper headlines on the other) sets the tone for the author's no doubt sincere but grossly biased account of the consequences of oral contraception. The book is semi-autobiographical, recounting the author's development from being an enthusiastic prescriber of and researcher on the Pill to her present extreme position of advising that no women should ever take the Pill. The problem, however, is that from the point at which she decided that oral contraception was a bad thing, she seems to have lost any capacity to assess the evidence objectively. She states (correctly) that negative associations between the Pill and disease do not prove a protective effect, but repeatedly assumes that positive associations are proof of causation. She explains away all reassuring findings of cohort studies by alleging that (a) most unhealthy women would be denied the Pill initially so must be in the control group; (b) most women will have such severe sideeffects from the Pill that they will drop out and be excluded from the analysis, or even counted as controls; (c) many or most of the controls will be receiving other hormones - thus only the 'tough' healthy individuals taking the Pill are compared with invalid controls. I doubt whether the researchers in the major cohort studies would recognise this description of their life's work - but in any event, if it were true, it is difficult to understand how so many reports of adverse side-effects have emerged from cohort studies.

The style of the book will certainly not appeal to medical readers. Each chapter starts with a 'common belief' then refuted by a 'fact', but Dr Grant refutes her own 'facts'. For example, on page 19 she states that commonly used Pills have an almost identical hormone balance, then on page 53 says, blood levels of Pill progesterone vary by a factor of ten. The book is full of anecdotes about individual women (such as one who had years of ill-health after two oral contraceptive tablets) and astonishing statements such as 'many women who need kidney transplants could have had their kidneys damaged by taking the Pill' or 'ballet teachers in London have complained that their pupils are now having more unexpected fractures'. The Pill is blamed for increases in violence to children divorce, suicide and accidental death among other things. Some references are given but most of the statements are quite unsupported.

I fear, however, that the book, with its lurid cover, its apparently scientific approach and its alarmist message will sell well to the general public, and that Dr Grant will have done a disservice to women by denying them an objective assessment of the advantages and disadvantages of this important method of contraception. There is some very loosely relevant material about 'clinical ecology' in which Dr Grant is now in private practice. Her proposal on contraception is that young wome should abstain from sex, and old couples should use barrier methods. $\mathrm{\sigma}$ do not consider that she has made he case in this book and would not recommend it as a source of enlightenment.

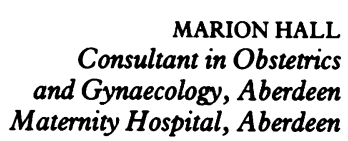

MARION HALL 